\title{
Editorial
}

\section{PREVENCIÓN DE RIESGOS}

Durante el mes de agosto se dieron a conocer los últimos índices de Accidentabilidad a nivel nacional, correspondiente a los últimos doce meses móviles. Durante ese periodo, la Asociación Chilena de Seguridad (ACHS) logró la meta propuesta por el Gobierno para el 2014, referida a bajar la Accidentabilidad de las empresas asociadas a menos del 4\% (específicamente, la ACHS llegó a un 3.95\%), la que se propuso con posterioridad al accidente mundialmente conocido en la mina San José. Cabe destacar que en Chile se observan niveles de Accidentabilidad similares a los de países desarrollados, indicio de un buen funcionamiento del sistema de mutualidades, aunque los índices de Accidentabilidad se encontraban desde hace ya varios años en un estancamiento e inclusive habian aumentado levemente. Sin embargo, en

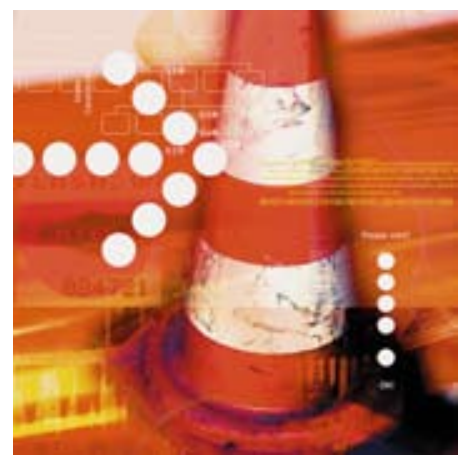

un contexto donde las formas del trabajo van cambiando, en tanto cambia la economía, cambian las tecnologías, nacen nuevas empresas, otras se fusionan; en un mundo globalizado en donde la única constante es el cambio, la prevención debe adaptarse a ellos, debiendo asumir el desafío de ser efectiva tanto en una empresa transnacional como en una pequeña Pyme. Este desafío debe ser tomado como una invitación a la creatividad y al estudio de la prevención de riesgos de una manera científica, a través de un método universal que nos permita generar nueva información, sistematizarla, evaluarla y reproducirla. Así, generar una espiral de conocimiento constante en donde este pueda ser construido y reconstruido con la finalidad de tener las mejores prácticas en todas y cada una de las empresas de nuestro país; los últimos dos años se ha observado una baja progresiva en la Accidentabilidad en las empresas asociadas a la ACHS, lo que se debe a cambios significativos en la forma de hacer prevención, principalmente referidos a la implementación de un modelo de gestión preventiva integral que, según Cristóbal Prado, Gerente General de ACHS, "tiene como pilares el diseño de planes especializados por sector productivo, la entrega de capacitación diferenciada según rubro y cargo, la utilización de metodologías de vanguardia y el abordaje de los riesgos psicosociales en el trabajo, los cuales hacen que los trabajadores estén más propensos a accidentarse”. En este modelo de gestión se destaca el rol que tiene la capacitación como un elemento que modifica las conductas riesgosas a través del aprendizaje de los trabajadores.

Asimismo, la responsabilidad social empresarial es otro de los factores que impactan al generar un mayor compromiso de las empresas respecto de la seguridad de sus trabajadores, reflejado en una mayor colaboración entre las empresas y la ACHS.

Es de vital importancia conceptualizar la prevención como un trabajo que se construye y evalúa de forma permanente, situada en empresas con culturas organizacionales disímiles, con rubros y trabajadores distintos unos de otros. Esto es precisamente lo que la ACHS -en asociación con INACAP - ha logrado al generar más de 120 cursos para trabajadores de nivel operario, supervisores y ejecutivos de 14 sectores económicos distintos. De aquí se desprenden tres grandes beneficios: primero, hará más productivas a las empresas que tomen la prevención como un elemento esencial dentro de sus modelos de negocios; también nos hará un país más competitivo a nivel regional y mundial; y, por último, lo más importante, brindará la tranquilidad a los trabajadores y a sus familias al saber que las labores que realizan son más sanas y seguras. El drama que vive una familia cuando alguno de sus integrantes sufre un accidente es devastador, y más aun cuando este es el jefe de hogar o quien aporta con el sustento para el grupo familiar. Es por esto que con la prevención de accidentes laborales ganamos todos, ganan las empresas, ganan las familias $\mathrm{y}$, en consecuencia, gana el país en su conjunto. La prevención de riesgos es una tarea noble y apasionante que debe tener mayor importancia de la que hoy en día tiene en nuestra sociedad. 